\title{
Assessment of the impacts of the consumers' awareness of organic food on consumption behavior
}

\author{
Bekir DEMIRTAS ${ }^{1 *}$
}

\begin{abstract}
Consumer demand for organic foods has increased significantly in recent years in the world. Consumers are influenced by various internal/external factors when purchasing food products. The aim of this study is to determine the effects of knowledge variable on consumers' purchasing or consuming behavior for organic foods together with other factors in Turkey (Hatay City). For this purpose, the effects of consumers' organic product knowledge levels are examined within the frame of Theory of Planned Behavior. The data of 431 consumers analyzed in the model were collected in 2017 with a 21 scale questionnaire and analyzed with Structural Equation Model. According to the results of the model analysis, a significant part of the variance in consumers' organic food demand (61\%) was explained by the organic food knowledge variable. Reducing consumption obstacles, along with efforts to increase the organic food knowledge of consumers, will increase organic demand. While trying to increase the supply of organic products especially in regions where consumers are concentrated, the food production sector should also focus on informing, raising awareness and promoting. The actual buying behavior in organic food products should be examined in more detail in terms of motivation sources and obstacles.
\end{abstract}

Keywords: consumer behavior; organic food; organic knowledge; the theory of planned behavior; Turkey.

Practical Application: For the development of consumption in organic food products, many factors that are seen among consumption obstacles are actually related to consumer knowledge. For this reason, organic product producers and marketers should focus more on informing and raising awareness among consumers.

\section{Introduction}

The demand for organic foods, which have shown a significant upward trend in the world in recent years, shows a similar tendency in Turkey as well. In addition to the concerns about conventional food, the health and environmental sensitivities of consumers, the increase of social knowledge, consciousness and education level and improvements in consumer income level have been effective in the increase of organic food consumption. (Chen et al., 2014; Shashi et al., 2015; Tsai et al., 2015; Agovino et al., 2017; Savita \& Verma, 2017; Chekima et al., 2017; Lian, 2017; Rana \& Paul, 2017; Oroian et al., 2017; Asif et al., 2018; Apaolaza et al., 2018; Hansen et al., 2018; Gomiero, 2018). In addition to these, consumers find organic foods more nutritious and tasty than traditional products. There are some research that revealed that some factors outside these also motivate consumers to consume organic food. (Dagistan et al., 2009; Smith \& Paladino, 2010; Shafie \& Rennie, 2012; Kapuge, 2016; Teng \& Lu, 2016; Boizot-Szantai et al., 2017; Du et al., 2017; Joshi \& Rahman, 2017; Singh \& Verma, 2017). There are also factors that prevent the organic food consumption. Foremost among these are high prices, deficiencies in consumer awareness and promotion, low availability (irregularity, limitations or lack of varieties) and consequently low consumption. (Chakrabarti, 2010; Xie et al., 2015; Bryła, 2016; Liobikienè et al., 2016; Du et al., 2017; Savita \& Verma, 2017). The common view of the previous literature is that consumers prefer organic foods because they are safer, healthier, and sensually superior to their traditional alternatives, as they feed themselves and their families. However, even though there are high consciousness and awareness due to the abovementioned consumption obstacles, situations in which real purchasing cannot be realized are frequently seen.

The conceptual framework for the consumption of organic foods is based on the Theory of Planned Behavior (TPB). TPB presents the most popular theoretical framework that explains the determinants and pioneers of buying behavior and intentions of consumers. For this reason, TPB also provides a sound theoretical structure for evaluating consumers' perceptions of organic foods, since the theory tries to explain the underlying reasons for individual behavior. In the expanded model, consumers' knowledge about organic foods is included. The theory of planned behavior has been widely applied to estimate various human behaviors and has been used in a number of empirical studies on organic food consumption (Hoppe et al., 2013; Kuran \& Mihić, 2014; Seo et al., 2014; Ajzen, 2015; Tsai et al., 2015; Liobikienė et al., 2016; Paul et al., 2016; Kumar et al., 2017; Maichum et al., 2017; Shin et al., 2018). In a survey conducted in Turkey, Iran and Pakistan, it was determined that the intention of purchasing organic food could be better predicted by attitude and health consciousness, and that increase in consumers' awareness of organic products positively affects their purchasing intention (Asif et al., 2018). 
TPB suggests three determinants that explain one's behavioral intent: attitude, subjective norm, and perceived behavioral control (Ajzen, 1991). Attitude is the degree to which a person has a positive or negative evaluation of a behavior. The subjective norm represents the social effect on the theory and is defined as "performing the behavior or perceived social pressure to perform the behavior". In other words, "a person's belief that others should engage in a certain behavior". Perceived behavioral control is "the ease or difficulty of conducting behavior" and a reflection of previous experiences and possible obstacles (Ajzen, 1991). According to theory, the behavior of the consumer is a function of the intention to achieve that behavior, whereas intention is based on perceived behavioral control of attitude, subjective norm and behavior and these factors are determined according to behavioral, normative, and control beliefs, respectively. The theory also allows us to estimate the intent and behavior of choice between different brands or products (Ajzen, 2015). Many studies only explain intention and generally assume that intention is a good predictor of behavior and it fully influences the effect of attitude and subjective norm of behavior (Gracia \& Magistris, 2013; Wu \& Chen, 2014). In addition, Han \& Kim (2010) reported that intention was still accepted as the best predictor of behavior.

Although the demand of the organic food market and organic food is increasing in Turkey, the literature on organic food consumption is not very extensive (Yilmaz \& Ilter, 2017). In this study, the effects of the knowledge level about organic food products of a group of consumers in Turkey, on attitude, subjective norm and perceived behavioral control, consumer intentions and behavior are presented. It is aimed to determine the effects of increasing food knowledge on consumers' intention to purchase and behavior.

\subsection{Conceptual framework and hypotheses}

\section{Attitude}

With a positive attitude of consumers towards organic food, the health concerns (especially in families with children and infants) of traditionally produced foods come to the forefront. Other than that, environmental knowledge and consciousness are other sources of motivation and contribute to the positive attitude of consumers. Product quality (sensory qualities such as good appearance and smell, and being delicious, healthy and safe) is among the factors that increase the positive attitude. It has been determined that women have more positive attitudes towards organic food than male consumers (Paul \& Rana, 2012). Increases in education and income levels are other sources of motivation that positively affect the attitude towards organic food. Moreover, the fact that consumers are older increases the positive attitudes. It has been determined that consumption of organic food is seen in some consumer groups as a symbol of fashion and status and such groups show a positive attitude towards organic consumption. It has been determined that living areas have an impact on organic food consumption, and in this regard, people living in cities have come forward (Chen et al., 2014; Xie et al., 2015; Kapuge, 2016; Misra \& Singh, 2016; Agovino et al., 2017; David \& Ardiansyah, 2017; Du et al., 2017; Joshi \& Rahman, 2017; Lian, 2017; Asif et al., 2018; Hansen et al., 2018). Taking these results into consideration, consumers are expected to have positive attitudes toward organic products.

H1: There is a positive relationship between consumers' attitudes towards purchasing organic products and their intention to buy organic products.

\section{Subjective Norms (SN)}

Subjective norms have a direct impact on consumers' purchasing intentions and behaviors. Particularly the attitudes and behaviors of individuals in economically and socially developed countries are highly related to subjective norms. Consumers' families, relatives, friends, and colleagues determine the subjective norms. Thus, the people around the consumers shape the attitudes of the individual (Du et al., 2017; Singh \& Verma, 2017; Teng \& Lu, 2016; Yilmaz \& Ilter, 2017; Hansen et al., 2018). As a result, subjective norms are an important determinant of organic purchase intent and an important factor. For this reason, we can suggest the following hypothesis;

$\mathrm{H} 2$ : There is a positive relationship between consumers' intentions to purchase organic products and personal and social norms.

\section{Perceived Behavioral Control (PBC)}

Perceived ease and difficulties about behavioral control and past experiences are influential in the emergence of behavioral intent and behavior. Moreover, in theory, the perceived behavioral control must occur before the intention is formed. Together with the perceived difficulties and eases in purchasing organic food products, past experiences are factors that determine behavioral intent and behavior. In many studies, it has been suggested that there is a positive relationship between the ability to control consumer behavior individually and the intention to purchase (Chen et al., 2014; Bryła, 2016; Kapuge, 2016; Chekima et al., 2017; Hansen et al., 2018; Lian, 2017; Maichum et al., 2017; Oroian et al., 2017; Savita \& Verma, 2017; Asif et al., 2018). For this reason, we can suggest the following assumptions;

H3: There is a positive relationship between consumers' perceived behavioral control and the intention to purchase organic foods.

H4: There is a positive relationship between perceived behavioral control of consumers and organic buying behavior.

\section{Organic food Knowledge (OK)}

Consumer knowledge, consciousness and beliefs about the environmental benefits of organic products are determinants of organic consumption. Purchasing/consuming organic products and acquiring knowledge about organic products in an active or passive manner develop familiarities with these products. As individuals acquire direct or indirect experience with organic products, they get a solid grasp of distinctive and enduring characteristics (Du et al., 2017). Due to the economic and social developments in Turkey, differences in consumer preferences for food have begun to emerge. Especially positive developments in fields such as education, income and urbanization are the 
leading factors that increase the knowledge and consciousness level of consumers. Media and social communication channels also made important contributions to these developments (Unusan, 2007; Yilmaz \& Ilter, 2017). Today, consumers tend to control food production processes more tightly and question the reliability and health effects of food produced by conventional methods. The production processes of organic food products, such as certification, labeling and inspection are monitored by consumers. As they have enough information about organic products, consumers will have a positive attitude towards these products. Therefore, we can speak of a positive correlation between purchasing intention and having knowledge. The general assessments that occurred in society also affect the behavior of people. For this reason, those who act according to social norms will direct their norms according to the social sensitivity towards organic products. Similarly, having enough knowledge in a subject has improved the ability to control the perceived behavior of people (Chakrabarti, 2010; Shafie \& Rennie, 2012; Hoppe et al., 2013; Bryła, 2016; Kapuge, 2016; Liobikienè et al., 2016; David \& Ardiansyah, 2017; Joshi \& Rahman, 2017; Kumar et al., 2017; Oroian et al., 2017; Asif et al., 2018). Today, it can be assumed that consumers have more knowledge about organic food products. For this reason, it is considered that there is a positive relationship between consumers' level of organic food knowledge and attitudes, individual-social norms and perceived behavioral controls.

H5: There is a positive relationship between the consumers' organic food knowledge and attitudes towards organic foods.

H6: There is a positive relationship between consumers' organic food knowledge and their individual and social norms towards organic foods.

H7: There is a positive relationship between consumers' organic food knowledge and perceived behavioral control towards organic food.

\section{Behavioral Intention (BI)}

TPB's central dependent variable is the consumer's intent, which is an indicator that one is ready to behave in a certain way (Ajzen, 1991). Many studies only explain intentions and generally assume that behavior is a good predictor of intent. It has been determined that subjective norms and attitude towards behavior have positive effect on the intention to purchase organic food products (Seo et al., 2014; Shashi et al., 2015; Joshi \& Rahman, 2017; Rana \& Paul, 2017; Savita \& Verma, 2017; Singh \& Verma, 2017). The intent is seen as the most important factor in influencing performance of the behavior. For this reason, the consumers' behavior is a function of the intention to perform the said behavior. It is based on intent, attitude, subjective norm, perceived behavioral control of intention and these factors are determined according to behavioral, normative and control beliefs, respectively. For this reason, the following hypothesis has been given.

H8: There is a positive relationship between the behavioral intentions of consumers for purchasing organic foods and purchasing behavior of organic foods.

\section{Material and methods}

In this study, the Eastern Mediterranean Region, which is located in the third sub-region of the Mediterranean Region determined by TR6 in the Turkey Statistical Region Units Classification, was selected. The data of 431 samples selected in Hatay province, which is the largest settlement area in this region, are used for sampling. It is estimated that since the sample size is more than 400 , which is recommended for Structural Equation Modeling (SEM), it is enough to qualify. The primary goal of an SEM analysis is to confirm research hypotheses about the observed means, variances, and covariance's of a set of variables. The hypotheses are represented by a number of structural parameters (e.g., factor loadings, regression paths) that is smaller than the number of observed parameters. As a confirmatory approach, it is crucial for researchers using SEM to test models that have strong theoretical or empirical foundations (Hair et al., 2014).

The data are obtained from consumers in the vicinity of large shopping malls located in 2 districts (İskenderun and Kırıkhan districts) of the Hatay city center in the summer of 2017. Adults who are over 18 years of age are targeted for they are expected to be households responsible for food purchases. This study is considered to be important because it is the first study to examine the behavior of purchasing organic products made in the region, and the results can be extended to other settlements of the region. The data collection survey instrument is designed as two sections. In the first part, consumers' demographic data (sex, age, family size, marital status, place of residence, education level, working status and average monthly income) were included. In the second part, 22 items ( 1 strongly disagree to 5 strongly agree) of the 5-Likert scale belonging to the model designed in the research were included. The distribution of scales according to organic information and TPB is given in Table 1. The scales used to determine the organic food purchasing behaviors of the consumers were derived from previous studies (Hoppe et al., 2013; Seo et al., 2014; Misra \& Singh, 2016; Teng \& Lu, 2016; Joshi \& Rahman, 2017; Lian, 2017; Maichum et al., 2017; Singh \& Verma, 2017; Hansen et al., 2018; Shin et al., 2018) and adapted to the conditions of Turkey. In addition to this, in the development of the model, TPB and studies regarding the preparation of questionnaire were also used (Ajzen, 2013). The prepared questionnaire was applied as a pre-test for 30 consumers for the test of model validity and reliability and the final content of the questionnaires is arranged according to the results obtained. The measure items were checked with various statistics in terms of skewness, kurtosis, validity, and reliability and it was seen that there was no problem. Descriptive statistics of the data and SPSS 22.0 and AMOS 22.0 programs were used for SEM analysis.

In the model; attitudes, subjective norms and perceived behavioral control elements are considered as independent variables from TPB elements. It is accepted that these variables will be sufficient to predict the organic food consumption behavior and intention. According to the theory, in order for a behavior to take place, it is first necessary to form an intention for that behavior. The second part of the theory consists of belief dimensions (behavior beliefs, normative beliefs, control beliefs). Attitudes, subjective norms, and beliefs that are cognitive and 
Table 1. Descriptive statistics of participants' TPB and organic food knowledge $(n=431)$.

\begin{tabular}{|c|c|c|}
\hline Indicators / Measurement items ${ }^{*}$ & Average & S.D. \\
\hline Attitude towards organic food consumption (A) & 4.061 & 0.573 \\
\hline A1: I think organic food consumption is healthy. & 4.327 & 0.802 \\
\hline A2: Organic food products have higher taste than conventional one. & 3.666 & 0.774 \\
\hline A3: Organic foods have no harmful effects on human health. & 4.190 & 1.059 \\
\hline Subjective norm (SN) & 3.019 & 0.942 \\
\hline SN1: People in my family think buying organic food is a good idea. & 3.123 & 1.271 \\
\hline SN2: My friends' positive thoughts are affecting me to buy organic products. & 2.889 & 1.021 \\
\hline SN3: People who are important to me want me to choose organic foods. & 3.046 & 0.999 \\
\hline Perceived behavioral control (PBC) & 3.722 & 0.533 \\
\hline PBC1: I am sure I can consume more organic food when I want. & 3.190 & 0.830 \\
\hline PBC2: I believe that my ability to buy organic products. & 4.283 & 0.815 \\
\hline PBC3: I have time and desire to consume organic foods. & 4.049 & 0.759 \\
\hline PBC4Despite being expensive. I prefer to buy organic food products. & 3.367 & 0.709 \\
\hline Organic knowledge (OK) & 3.662 & 0.917 \\
\hline OK1: I know the process of organic products. & 3.269 & 0.861 \\
\hline OK2: I know that organic foods are safer for eating. & 3.968 & 1.091 \\
\hline OK3: I realize that food is not organic or organic. & 3.749 & 1.062 \\
\hline Behavioral Intention of organic food consumption (BI) & 4.263 & 0.713 \\
\hline BI1: I have the goal of consuming organic foods as much as possible. & 4.039 & 0.989 \\
\hline BI2: I will consume organic food to ensure my health. & 4.223 & 0.931 \\
\hline BI3: I want to consume more organic food for high quality life. & 4.432 & 0.725 \\
\hline BI4: I can buy organic food products. & 4.531 & 0.694 \\
\hline BI5: I want to consume organic food in the next two weeks. & 4.090 & 0.806 \\
\hline Organic food consumption behavior (B) & 3.747 & 0.454 \\
\hline B1: I consume organic foods even at higher prices. & 3.798 & 0.746 \\
\hline B2: I get organic food regularly. & 2.819 & 0.602 \\
\hline B3: I am trying to consume organic foods for health benefits. & 4.014 & 0.774 \\
\hline B4: I recommend organic foods that I have consumed nearby. & 4.357 & 0.619 \\
\hline
\end{tabular}

${ }^{*} 5$ point Likert scale; $1=$ strongly disagree. $5=$ strongly agree; S:D.: Standard Deviation.

affective bases of perceived behavior control play a central role in TPB (Ajzen, 2005). The TPB variables do not provide any predictions or conclusions about the intentions or person's information about the behavior. For this reason, the model is expanded and consumers' information on organic foods variable is added. The contribution of the consumer organic information variable to predict the intention or behavior, and whether it can be relied upon will be tested. As a result, whether the consumer information and the expansion in the TPB model are meaningful or not will be proven. Consumer data below the average level of knowledge (3) according to the 5-point Likert scale was excluded from the assessment. Organic Food Information of the participants in our study was determined on a 3 -item scale, and response to the assessed participants are above the average value.

\section{Results and discussion}

\subsection{Demography}

The distribution of the characteristics of participants according to different socioeconomic indicators is grouped in Table 2. In the distribution of the participants by gender, the number of males was $12.3 \%$ higher than females. The number of married participants was the more with 283 (66\%). In terms of education level, participants were mostly at the high school level or below with $69 \%$. In terms of the number of people in the families of the consumers, the highest rate is $44 \%$ with $4-5$ people. The distribution of the consumers' living areas who are included in the sample, is similar to that of Turkey. This similarity has also been achieved in terms of gender, marital status, educational level and the number of individuals in the family. It can be concluded that the demographic and socio-economic indicators of the sample examined in this study are suitable for making generalizations for the entire region.

\subsection{Measures}

The mean values of the responses of the consumers to the scale items specified in the expanded TPB framework and standard deviation values (Table 1) and the scale items for each of the variables are shown below. It can be said that the average of consumers' attitudes towards consuming/purchasing organic products is considerably good $(\mathrm{A}=4.061)$. According to the 5-point Likert scale of $\mathrm{SN}$, another variant of the model, the average of the scale items was close to the neutral value $(\mathrm{SN}=3.019)$; However, the average of the perceived behavioral control items $(\mathrm{PBC}=3.722)$ was higher. The mean of the scale items of the other variables examined in the model showed quite good values for the average level of organic knowledge $(\mathrm{OK}=3.662)$, the behavioral intention for organic products $(\mathrm{BI}=4.263)$ and behavior $(\mathrm{B}=3.747)$. The TPB variables measured within the 
framework of the consumer's research model produced generally good values, but it is worth to mention that the $\mathrm{SN}$ values are lower than the other variable averages.

\subsection{Measurement model results}

For the measurement model, the factor loading in each structure is ranged from 0.805 to 0.894 and since all of them are statistically significant $(\mathrm{p}<0.01)$, these results show the reliability of the scale. Hair at al. (2014) gives level of 0.7 in Composite Reliability as an acceptable value, and at least 0.5 for Average Variance Extracted (AVE). Composite reliability of constructs is ranged from 0.87 to 0.92 and AVE values are ranged from 0.62 to 0.74 . Accordingly, internal consistency and construct validity in the measurement model are found to be at a fairly good level (Table 3). According to this, internal consistency and construct validity of the measurement model is found to be at a fairly good level (Table 3).

Table 2. Socioeconomic and demographic characteristics of research participants $(n=431)$.

\begin{tabular}{|c|c|c|c|c|c|c|c|}
\hline \multicolumn{2}{|c|}{ Items } & \multirow{2}{*}{$\frac{\mathrm{n}}{242}$} & \multirow{2}{*}{$\begin{array}{c}\% \\
56.15\end{array}$} & \multicolumn{2}{|c|}{ Items } & \multirow{2}{*}{$\begin{array}{c}\mathrm{n} \\
90\end{array}$} & \multirow{2}{*}{$\begin{array}{c}\% \\
20.88\end{array}$} \\
\hline Gender & Male & & & \multirow{5}{*}{ Age groups } & $18-24$ & & \\
\hline Gender & Female & 189 & 43.85 & & $25-34$ & 135 & 31.32 \\
\hline \multirow{3}{*}{ Marital status } & Single & 132 & 30.63 & & $35-44$ & 115 & 26.68 \\
\hline & Married & 283 & 65.66 & & $45-54$ & 74 & 17.17 \\
\hline & $\begin{array}{l}\text { Divorced/ } \\
\text { Widowed }\end{array}$ & 16 & 3.71 & & $55-64$ & 15 & 3.48 \\
\hline \multirow{5}{*}{ Education level } & $\begin{array}{c}\text { Less than High } \\
\text { School }\end{array}$ & 149 & 34.57 & \multirow{5}{*}{ Working status } & $65-\leq$ & 2 & 0.46 \\
\hline & High School & 148 & 34.34 & & Student & 121 & 28.07 \\
\hline & Junior college & 67 & 15.55 & & Housewife & 88 & 20.42 \\
\hline & Undergraduate & 61 & 14.15 & & Unemployed & 62 & 14.39 \\
\hline & Graduate & 6 & 1.39 & & Employed & 137 & 31.79 \\
\hline \multirow{4}{*}{ Family size } & 1 & 4 & 0.93 & \multirow{7}{*}{$\begin{array}{l}\text { Monthly income } \\
\text { (Turkish Lira) }\end{array}$} & Retired & 23 & 5.34 \\
\hline & $2-3$ & 90 & 20.88 & & $\leq-1500$ & 93 & 21.58 \\
\hline & $4-5$ & 190 & 44.08 & & $1501-2000$ & 83 & 19.26 \\
\hline & $6-\leq$ & 147 & 34.11 & & $2001-2500$ & 130 & 30.16 \\
\hline \multirow{3}{*}{$\begin{array}{l}\text { Place of } \\
\text { residence }\end{array}$} & Provincial center & 178 & 41.30 & & $2501-3000$ & 66 & 15.31 \\
\hline & County town & 181 & 42.00 & & $3001-3500$ & 47 & 10.90 \\
\hline & Village & 72 & 16.71 & & $3501-\leq$ & 12 & 2.78 \\
\hline
\end{tabular}

Table 3. Measurement model structure validation.

\begin{tabular}{|c|c|c|c|c|c|}
\hline \multirow{2}{*}{ Constructs } & \multirow{2}{*}{ Indicators } & \multicolumn{2}{|c|}{ Item reliability } & \multicolumn{2}{|c|}{ Convergent validity } \\
\hline & & $\lambda_{i}$ & a & AVE & $\rho_{c}$ \\
\hline \multirow{2}{*}{ Organic Knowledge (OK) } & OK1 & 0.596 & \multirow{2}{*}{0.894} & \multirow{2}{*}{0.610} & \multirow{2}{*}{0.821} \\
\hline & OK3 & 0.639 & & & \\
\hline \multirow[b]{2}{*}{ Attitude Toward Consumption (OA) } & OA1 & 0.601 & \multirow[b]{2}{*}{0.805} & \multirow[b]{2}{*}{0.627} & \multirow[b]{2}{*}{0.831} \\
\hline & OA2 & 0.877 & & & \\
\hline \multirow[t]{2}{*}{ Subjective Norm (SN) } & SN2 & 0.781 & \multirow[t]{2}{*}{0.813} & \multirow[t]{2}{*}{0.520} & \multirow[t]{2}{*}{0.764} \\
\hline & SN3 & 0.679 & & & \\
\hline \multirow{3}{*}{ Perceived Behavioral Control (PBC) } & PBC1 & 0.702 & \multirow{3}{*}{0.863} & \multirow{3}{*}{0.526} & \multirow{3}{*}{0.815} \\
\hline & $\mathrm{PBC} 2$ & 0.831 & & & \\
\hline & PBC3 & 0.665 & & & \\
\hline \multirow{2}{*}{ Behavioral Intention Towards Organic Food Consumption (BI) } & BI4 & 0.830 & \multirow{2}{*}{0.815} & \multirow{2}{*}{0.553} & \multirow{2}{*}{0.860} \\
\hline & BI5 & 0.688 & & & \\
\hline \multirow{4}{*}{ Organic Food Consumption Behavior (B) } & B1 & 0.735 & \multirow{4}{*}{0.862} & \multirow{4}{*}{0.720} & \multirow{4}{*}{0.824} \\
\hline & $\mathrm{B} 2$ & 0.702 & & & \\
\hline & B3 & 0.782 & & & \\
\hline & B4 & 0.718 & & & \\
\hline
\end{tabular}

The estimated factor loadings are important at the level $\mathrm{p}<0.001$. Note: $\alpha$ : Cronbach's alpha; $\lambda_{i}$ : Factor loadings. AVE: Average variance extracted. $\rho_{c}=$ Composite reliability. 
When the AVE values of the constructs in the measurement model are examined, the consumer's organic product knowledge account for $61 \%$ of the variance in the model. Among the variables in the model, the highest explained variance value is obtained from attitude towards consumption (63\%) and the lowest explained variance value was obtained from subjective norms. The total variance value of the organic food consumption in model was determined as $72 \%$. This result shows that the predictive power of the variables included in the model is at a fairly good level.

\subsection{Goodness of fit results of structural model}

When model's overall goodness-of-fit indices are examined, $\left[\begin{array}{l}\chi^{2}=244.584(p<0.001), d f=201, \chi^{2} / s d=1.217, G F I=0.905, \\ A G F I=0.929, C F I=0.957, R M S E A=0.065\end{array}\right]$ very good values have been achieved, that is the data used in the model fit very well with the model structures. If the goodness of fit indices in SEM analysis is estimated between $2 \leq \chi^{2} / s d \leq 3,0.90 \leq G F I \leq 0.95,0.85 \leq A G F I \leq 0.90,0.90 \leq C F I \leq 0.95$, $0.90 \leq T L I \leq 0.95,0.05 \leq R M S E A \leq 0.08$

values, it is considered to be significant and meaningful (Kline, 2011). We can also say that some of the goodness of fit indices produced in our study point to perfect fit $\left(\chi^{2} / \mathrm{sd}\right.$, AGFI and CFI). The results generally show that the data of the study fit well with the model and the model is confirmed.

\subsection{Hypothesis results}

The $\mathrm{H} 1$ hypothesis, which suggests that there is a positive relationship between the attitudes of consumers towards organic products and their behavioral intentions towards buying/consuming, is verified $(\beta=0.129, \mathrm{p}<0.05)$. Also, the $\mathrm{H} 2$ hypothesis was also confirmed $(\beta=0.581, \mathrm{p}<0.001)$, which suggests a positive relationship between consumers' subjective norms and purchasing intentions of organic foods. The $\mathrm{H} 3$ hypothesis, which suggests the existence of a positive relationship between the perceived behavioral control of consumers and the intention to buy organic food products, was proven to be positive $(\beta=0.209, \mathrm{p}<0.01)$. Hypotheses ( $\mathrm{H} 4, \mathrm{H} 5$ and $\mathrm{H} 6)$, which suggest that the positive correlation between consumers' knowledge of organic food products and their behavioral intentions, subjective norms, and perceived behavioral controls is significant and important, are supported $(\beta=0.719, \mathrm{p}<0.001, \beta=0.839, \mathrm{p}<0.001$ and $\beta=0.435, \mathrm{p}<0.001$ respectively). Thus, these positive interactions demonstrate the importance of consumers' knowledge and consciousness about organic products. The relationship between perceived behavioral control and organic food purchasing behavior (H7), which is defined in another way, were found to be significant $(\beta=0.281, \mathrm{p}<0.009)$. In the final, the hypothesis (H8) which suggest that the consumers' behavioral intentions to purchase organic food products, is related positively to purchasing behavior is confirmed $(\beta=0.750, \mathrm{p}<0.001)$ (Table 4$)$.

The results reveal that consumers' knowledge of organic food products positively predicts consumption of organic foods, behavioral intentions, subjective norms and perceived behavioral controls. Consumers' level of organic knowledge has a positive effect on consumption behaviors of organic, intent and behavior at a significant level. Among all TPB variables, consumer attitudes were found to be the most important variables that positively contributed to the model. This result shows parallelism with many previous empirical studies. In studies conducted in relation to TPP, it has been found that subjective norms and attitudes have a positive effect on the intention to purchase organic food (Savita \& Verma, 2017). In a TPB-applied study on organic food purchasing, it has been shown that organic food consumption habits, subjective norms, financial status, health awareness and knowledge about organic food have a significant impact on the intention to purchase organic food. Subjective norms, attitudes and health awareness have been identified as best predictions of the intention to purchase. Moreover, the relationship between the purchase of organic food and the intention to purchase organic food was found to be statistically significant (Kuran \& Mihić, 2014). In a study conducted in Turkey, a significant difference was found between consumers' food safety knowledge and attitudes, and education levels (Unusan, 2007). Factors that have positively influenced consumer attitudes according to previous literature (education level, health consciousness, awareness, etc.) in general are another expression of the organic information variable that we include in our study. For this reason, with a more general approach, with consumer's organic knowledge and consciousness levels affecting consumer attitudes positively, behavioral intent and behavior towards the consumption of organic products are also increasing.

Table 4. SEM results of planned behavior model in organic foods.

\begin{tabular}{ccccc}
\hline Paths & $\begin{array}{c}\text { Standardized path } \\
\text { coefficient }(\beta)\end{array}$ & t-value & Hypothesis results \\
\hline OA-->BI & 0.129 & 1.972 & 0.049 & 0.000 \\
SN-->BI & 0.581 & 8.985 & 0.010 & + \\
PBC-->BI & 0.209 & 2.572 & 0.000 & + \\
OK-->OA & 0.719 & 10.060 & 0.000 & + \\
OK-->SN & 0.839 & 16.782 & 0.000 & + \\
OK-->PBC & 0.435 & 8.550 & 0.009 & + \\
PBC-->B & 0.281 & 1.494 & 0.000 & + \\
BI-->B & 0.750 & 14.609 & + \\
\hline
\end{tabular}

OA: Attitude Toward Consumption. BI: Behavioral Intention. SN: Subjective Norm. PBC: Percieved Behavioral Control. OK: Organic Knowledge. B: Consumption Behavior. 


\section{Conclusion}

The consumers' behavior in terms of food purchasing/ consumption is determined by various factors. Most of the studies on organic consumption determinants and consumption motivations and obstacles of organic food products consist of information-based variables. For this reason, an important part of the behavior can be explained by measuring the level of consumer knowledge. The results of our study have revealed that consumers' knowledge about organic food products has a positive and significant impact on the intent and consumers' behavior. The analyzed model explains a significant part of the variance in consumer behavior. For this reason, consumers should be convinced through informing to stimulate the intention to buy, and this should be one of the strategies of rising demand for organic food. Policymakers should pay close attention to promoting awareness and consciousness levels and promoting the health benefits of organic foods in order to stimulate real purchasing actions. In terms of consumption of organic foods, the sources of motivation and obstacles vary according to the country. It is also necessary to focus on reducing consumption obstacles as well as specific motivational factors in publicity, training and campaign work for the increase of consumption of organic foods. In order to increase the demand for organic products, consumers, who are not sure about the accuracy of the products in terms of recognition and awareness, should be informed about the labeling and certification of organic products. It is important that the public and private sector organizations involved in the organic production process act together to ensure consumer confidence. Firms marketing organic food products should take into consideration that they can increase consumers' confidence in products with informative work. In promotional activities support from consumer associations and organic consumption groups should be received.

\section{References}

Agovino, M., Crociata, A., Quaglione, D., Sacco, P., \& Sarra, A. (2017). Good taste tastes good. Cultural capital as a determinant of organic food purchase by Italian consumers: Evidence and policy implications. Ecological Economics, 141, 66-75. http://dx.doi.org/10.1016/j. ecolecon.2017.05.029.

Ajzen, I. (1991). The theory of planned behavior. Organizational Behavior and Human Decision Processes, 50(2), 179-211. http:// dx.doi.org/10.1016/0749-5978(91)90020-T.

Ajzen, I. (2005). Attitudes, personality and behavior (2nd ed.). MiltonKeynes: McGraw- Hill Open University Press.

Ajzen, I. (2013). Theory of planned behaviour questionnaire. Galway: Measurement Instrument Database for the Social Science. Retrieved from http://www.midss.org/sites/default/files/tpb.construction.pdf

Ajzen, I. (2015). Consumer attitudes and behavior: the theory of planned behavior applied to food consumption decisions. Rivista di Economia Agraria, Anno LXX, 2, 121-138. http://dx.doi.org/10.13128/REA-18003.

Apaolaza, V., Hartmann, P., D’Souza, C., \& López, C. M. (2018). Eat organic - Feel good? The relationship between organic food consumption. health concern and subjective wellbeing. Food Quality and Preference, 63, 51-62. http://dx.doi.org/10.1016/j. foodqual.2017.07.011.

Asif, M., Xuhui, W., Nasiri, A., \& Ayyub, S. (2018). Determinant factors influencing organic food purchase intention and the moderating role of awareness: A comparative analysis. Food Quality and Preference, 63, 144-150. http://dx.doi.org/10.1016/j.foodqual.2017.08.006.

Boizot-Szantai, C., Hamza, O., \& Soler, L. G. (2017). Organic consumption and diet choice: An analysis based on food purchase data in France. Appetite, 117, 17-28. http://dx.doi.org/10.1016/j.appet.2017.06.003. PMid:28603060.

Bryła, P. (2016). Organic food consumption in Poland: Motives and barriers. Appetite, 105, 737-746. http://dx.doi.org/10.1016/j. appet.2016.07.012. PMid:27417333.

Chakrabarti, S. (2010). Factors influencing organic food purchase in India-expert survey insights. British Food Journal, 112(8), 902-915. http://dx.doi.org/10.1108/00070701011067497.

Chekima, B., Oswald, A. I., Wafa, S. A. W. S. K., \& Chekima, K. (2017). Narrowing the gap: factors driving organic food consumption. Journal of Cleaner Production, 166, 1438-1447. http://dx.doi.org/10.1016/j. jclepro.2017.08.086.

Chen, J., Lobo, A., \& Rajendran, N. (2014). Drivers of organic food purchase intentions in mainland China - evaluating potential customers' attitudes, demographics and segmentation. International Journal of Consumer Studies, 38(4), 346-356. http://dx.doi.org/10.1111/ijcs.12095.

Dagistan, E., Demirtas, B., Akpinar, M. G., Yilmaz, Y., Gul, M., \& Koc, B. (2009). Determination of organic fish purchase tendency of consumers: a case study for Hatay Province, Turkey. Journal of Animal and Veterinary Advances, 8, 1784-1789.

David, W., \& Ardiansyah, A. (2017). Perceptions of young consumers toward organic food in Indonesia. International Journal of Agricultural Resources, Governance and Ecology, 13(4), 315. http://dx.doi. org/10.1504/IJARGE.2017.088373.

Du, S., Bartels, J., Reinders, M., \& Sen, S. (2017). Organic consumption behavior: A social identification perspective. Food Quality and Preference, 62, 190-198. http://dx.doi.org/10.1016/j.foodqual.2017.07.009.

Gomiero, T. (2018). Food quality assessment in organic vs. conventional agricultural produce: findings and issues. Applied Soil Ecology, 123, 714-728. http://dx.doi.org/10.1016/j.apsoil.2017.10.014.

Gracia, A., \& Magistris, T. (2013). Organic food product purchase behaviour: a pilot study for urban consumer in the south of Italy. Spanish Journal of Agricultural Research, 5(4), 439-451. http://dx.doi. org/10.5424/sjar/2007054-5356.

Hair, J. K., Black, W. C., Babin, B. J., \& Anderson, R. E. (2014). Multivariate data analysis (7th ed.). Harlow: Pearson Education Limited.

Han, H., \& Kim, Y. (2010). An investigation of green hotel customers' decision formation: developing an extended model of the theory of planned behavior. International Journal of Hospitality Management, 29(4), 659-668. http://dx.doi.org/10.1016/j.ijhm.2010.01.001.

Hansen, T., Sørensen, M. I., \& Eriksen, M. L. R. (2018). How the interplay between consumer motivations and values influences organic food identity and behavior? Food Policy, 74, 39-52. http:// dx.doi.org/10.1016/j.foodpol.2017.11.003.

Hoppe, A., Vieira, L. M., \& Barcellos, M. D. D. (2013). Consumer behaviour towards organic food in Porto Alegre: an application of the Theory of Planned Behaviour. Revista de Economia e Sociologia Rural, 51(1), 69-90. http://dx.doi.org/10.1590/S0103-20032013000100004.

Joshi, Y., \& Rahman, Z. (2017). Investigating the determinants of consumers' sustainable purchase behaviour. Sustainable Production and Consumption, 10, 110-120. http://dx.doi.org/10.1016/j.spc.2017.02.002.

Kapuge, K. D. L. R. (2016). Determinants of organic food buying behavior: special reference to organic food purchase intention of Sri Lankan customers. Procedia Food Science, 6, 303-308. http:// dx.doi.org/10.1016/j.profoo.2016.02.060. 
Kline, R. B. (2011). Principle and practice of structural equation modeling (3th ed.). New York: The Guilford Press.

Kumar, B., Manrai, A. K., \& Manrai, L. A. (2017). Purchasing behaviour for environmentally sustainable products: A conceptual framework and empirical study. Journal of Retailing and Consumer Services, 34, 1-9. http://dx.doi.org/10.1016/j.jretconser.2016.09.004.

Kuran, L. M., \& Mihić, M. (2014). Applying the theory of planned behavior in the purchase of organic food. Tržište, 26(2), 179-197. Retrieved from https://hrcak.srce.hr/132724

Lian, S. B. (2017). What motivates consumers to purchase organic food in Malaysia? Asian Social Science, 13(9), 100-109. http://dx.doi. org/10.5539/ass.v13n9p100.

Liobikienė, G., Mandravickaite, J., \& Bernatonienė, J. (2016). Theory of planned behavior approach to understand the green purchasing behavior in the EU: a cross-cultural study. Ecological Economics, 125, 38-46. http://dx.doi.org/10.1016/j.ecolecon.2016.02.008.

Maichum, K., Parichatnon, S., \& Peng, K. C. (2017). Developing an extended Theory of Planned Behavior Model to investigate consumers' consumption behavior toward organic food: a case study in Thailand. International Journal of Scientific \& Technology Research, 6(1), 72-80.

Misra, R., \& Singh, D. (2016). An analysis of factors affecting growth of organic food perception of consumers in Delhi-NCR (India). British Food Journal, 118(9), 2308-2325. http://dx.doi.org/10.1108/ BFJ-02-2016-0080.

Oroian, C. F., Safirescu, C. O., Harun, R., Chiciudean, G. O., Arion, F. H., Muresan, I. C., \& Bordeanu, B. M. (2017). Consumers' attitudes towards organic products and sustainable development: a case study of Romania. Sustainability, 9(9), 1-14. http://dx.doi.org/10.3390/ su9091559.

Paul, J., \& Rana, J. (2012). Consumer behavior and purchase intention for organic food. Journal of Consumer Marketing, 29(6), 412-422. http://dx.doi.org/10.1108/07363761211259223.

Paul, J., Modi, A., \& Patel, J. (2016). Predicting green product consumption using theory of planned behavior and reasoned action. Journal of Retailing and Consumer Services, 29, 123-134. http://dx.doi. org/10.1016/j.jretconser.2015.11.006.

Rana, J., \& Paul, J. (2017). Consumer behavior and purchase intention for organic food: a review and research agenda. Journal of Retailing and Consumer Services, 38, 157-165. http://dx.doi.org/10.1016/j. jretconser.2017.06.004.

Savita, U., \& Verma, V. (2017). Influence of attitudes and subjective norms on intention to buy organic food: a literature review. In $\mathrm{U}$. Arora, A. Verma \& S. Singh (Eds.), Management insight - A glimpse of contemporary research (pp. 455-468). New Delhi: DBH Publishers and Distributors.
Seo, S., Kim, O. Y., \& Shim, S. (2014). Using the theory of planned behavior to determine factors influencing processed foods consumption behavior. Nutrition Research and Practice, 8(3), 327-335. http:// dx.doi.org/10.4162/nrp.2014.8.3.327. PMid:24944779.

Shafie, F. A., \& Rennie, D. (2012). Consumer perceptions towards organic food. Procedia: Social and Behavioral Sciences, 49, 360-367. http://dx.doi.org/10.1016/j.sbspro.2012.07.034.

Shashi, A. A., Kottala, S. Y., \& Singh, R. (2015). A review of sustainability, deterrents, personal values, attitudes and purchase intentions in the organic food supply chain. Pacific Science Review B: Humanities and Social Sciences, 1(3), 114-123. https://doi.org/10.1016/j.psrb.2016.09.003.

Shin, Y. H., Im, J., Jung, S. E., \& Severt, K. (2018). The theory of planned behavior and the norm activation model approach to consumer behavior regarding organic menus. International Journal of Hospitality Management, 69, 21-29. http://dx.doi.org/10.1016/j.ijhm.2017.10.011.

Singh, A., \& Verma, P. (2017). Factors influencing Indian consumers' actual buying behaviour towards organic food products. Journal of Cleaner Production, 167, 473-483. http://dx.doi.org/10.1016/j. jclepro.2017.08.106.

Smith, S., \& Paladino, A. (2010). Eating clean and green? Investigating consumer motivations towards the purchase of organic food. Australasian Marketing Journal, 18(2), 93-104. http://dx.doi. org/10.1016/j.ausmj.2010.01.001.

Teng, C. C., \& Lu, C. H. (2016). Organic food consumption in Taiwan: Motives. involvement. and purchase intention under the moderating role of uncertainty. Appetite, 105, 95-105. http://dx.doi.org/10.1016/j. appet.2016.05.006. PMid:27178878.

Tsai, H. H., Cheng, M. J., Hung, S. W., He, D. S., \& Wang, W. S. (2015, August 2-6). A study of organic food consumption behavior using the decomposed theory of planned behavior. In Portland International Conference on Management of Engineering and Technology. Portland: PICMET.

Unusan, N. (2007). Consumer food safety knowledge and practice in the home in Turkey. Food Control, 18(1), 45-51. http://dx.doi. org/10.1016/j.foodcont.2005.08.006.

Wu, S., \& Chen, J. (2014). A model of green consumption behavior constructed by the Theory of Planned Behavior. International Journal of Marketing Studies, 6(5), 119-132. http://dx.doi.org/10.5539/ijms. v6n5p119.

Xie, B., Wang, L., Yang, H., Wang, Y., \& Zhang, M. (2015). Consumer perceptions and attitudes of organic food products in Eastern China. British Food Journal, 117(3), 1105-1121. http://dx.doi.org/10.1108/ BFJ-09-2013-0255.

Yilmaz, B. S., \& Ilter, B. (2017). Motives underlying organic food consumption in Turkey: impact of health, environment and consumer values on purchase intentions. Economics World, 5(4), 333-345. 